\title{
Efficacy and Safety of Lurasidone in Adolescents with Schizophrenia: A 6-Week, Randomized Placebo-Controlled Study
}

\author{
Robert Goldman, PhD, Antony Loebel, MD, Josephine Cucchiaro, PhD, \\ Ling Deng, $\mathrm{PhD}$, and Robert L. Findling, MD, MBA ${ }^{2,3}$
}

\begin{abstract}
Objective: To evaluate the efficacy and safety of lurasidone in acutely symptomatic adolescent patients with schizophrenia. Methods: Patients aged 13-17 years were randomly assigned to 6 weeks of double-blind, fixed-dose lurasidone ( $40 \mathrm{or} 80 \mathrm{mg}$ / day) or placebo. Primary and key secondary efficacy measures were change from baseline to week 6 in the Positive and Negative Symptom Scale (PANSS) total score and Clinical Global Impressions-Severity (CGI-S) score, respectively, using mixed model for repeated measurement (MMRM) analysis. The proportion of patients achieving treatment response at endpoint, based on $\geq 20 \%$ reduction in PANSS total score, was analyzed using a logistic regression model.

Results: Least-squares (LS) mean change in PANSS total score from baseline to week 6 was -18.6 with lurasidone $40 \mathrm{mg}$ / day $(N=108 ; p<0.001$ vs. placebo; effect size $=0.51),-18.3$ with lurasidone $80 \mathrm{mg} /$ day $(N=106 ; p<0.001$ vs. placebo; effect size $=0.48)$, and -10.5 with placebo $(N=112)$. Similarly, LS mean change in CGI-S score from baseline to week 6 was significantly greater with lurasidone $40 \mathrm{mg} /$ day $(-1.0 ; p<0.001$; effect size $=0.49)$ and $80 \mathrm{mg} / \mathrm{day}(-0.9 ; p=0.0015$; effect size $=0.45$ ) compared with placebo $(-0.5)$. A significantly higher proportion of patients met responder criteria on lurasidone 40 and $80 \mathrm{mg} /$ day versus placebo $(63.9 \%$ and $65.1 \%$ vs. $42.0 \% ; p<0.001$ for both comparisons). The rate of study discontinuation was $10.3 \%$ in lurasidone-treated and $17.7 \%$ in placebo-treated patients. The most common adverse events (incidence $\geq 5 \%$ in either lurasidone dose group and at least twice the rate of placebo) for lurasidone $40 \mathrm{mg} / \mathrm{day}$, $80 \mathrm{mg} /$ day, and placebo, respectively, were nausea $(12.7 \%, 14.4 \%$, and $2.7 \%)$, somnolence $(9.1 \%, 11.5 \%$, and $5.4 \%)$, akathisia $(9.1 \%, 8.7 \%$, and $1.8 \%)$, vomiting $(8.2 \%, 6.7 \%$, and $1.8 \%)$, and sedation $(5.5 \%, 1.9 \%$, and $1.8 \%)$. Treatment with lurasidone was not associated with clinically meaningful effects on body weight, lipids, measures of glycemic control, or prolactin.

Conclusions: In this 6-week study, lurasidone at doses of 40 and $80 \mathrm{mg} /$ day demonstrated statistically significant and clinically meaningful symptom improvement in adolescent patients with schizophrenia. Lurasidone was generally well tolerated with few effects on weight and metabolic parameters, consistent with findings in adult patients with schizophrenia.
\end{abstract}

Keywords: lurasidone, adolescent, schizophrenia, clinical study, treatment

\section{Introduction}

$\mathbf{O}$ NSET OF SCHIZOPHRENIA commonly occurs during late adolescence or early adulthood (Hafner et al. 1993; Beratis et al. 1994; Hafner and Nowotny 1995). Although diagnostic criteria for schizophrenia are the same for youth as for adults (McClellan and Stock 2013), earlier onset (before age 18) is often characterized by greater symptom severity, more neurocognitive impairment, and higher rates of chronic functional impairment (Frazier et al. 2007, 2012). Functional deficits associated with early-onset schizophrenia include low educational achievement, limited ability to live independently, and persistent impairment in social functioning (Hollis 2000; Lay et al. 2000; Fleischhaker et al. 2005; Clemmensen et al. 2012; McClellan and Stock 2013).

\footnotetext{
${ }^{1}$ Sunovion Pharmaceuticals, Inc., Marlborough, Massachusetts.

${ }^{2}$ Johns Hopkins University, Baltimore, Maryland.

${ }^{3}$ Department of Psychiatry and Behavioral Sciences, Kennedy Krieger Institute and Johns Hopkins University, Baltimore, Maryland.

(C) Robert Goldman et al. 2017; Published by Mary Ann Liebert, Inc. This is an Open Access article distributed under the terms of the Creative Commons Attribution License, which permits unrestricted use, distribution, and reproduction in any medium, provided the original work is properly cited.
} 
Several atypical antipsychotic agents (aripiprazole, olanzapine, paliperidone, quetiapine, and risperidone) have demonstrated efficacy in the acute treatment of adolescents with schizophrenia (Findling et al. 2008, 2012; Haas et al. 2009; Kryzhanovskaya et al. 2009; Singh et al. 2011). Ongoing treatment with antipsychotic agents, in combination with psychotherapeutic interventions, is recommended for adolescent patients with schizophrenia (Young and Findling 2004; Masi and Liboni 2011; McClellan and Stock 2013). Tolerability and safety considerations are of particular importance in treatment selection because adolescents may be more vulnerable to the adverse effects associated with certain antipsychotic agents, including weight gain, metabolic and endocrine abnormalities, and extrapyramidal symptoms (Vitiello et al. 2009; Correll 2011; De Hert et al. 2011; Maayan and Correll 2011).

Lurasidone is an atypical antipsychotic agent with high binding affinity for $\mathrm{D}_{2}, 5-\mathrm{HT}_{2 \mathrm{~A}}$, and 5- $\mathrm{HT}_{7}$ receptors (antagonist); moderate affinity for $5-\mathrm{HT}_{1 \mathrm{~A}}$ receptors (partial agonist); and no appreciable affinity for $H_{1}$ and $M_{1}$ receptors (Ishibashi et al. 2010). Lurasidone has demonstrated efficacy and safety in the acute and long-term treatment of adults with schizophrenia in the dose range of 40 to $160 \mathrm{mg} /$ day (Nakamura et al. 2009; Meltzer et al. 2011; Citrome et al. 2012; Loebel et al. 2013a, 2013b; Nasrallah et al. 2013; Ogasa et al. 2013; Tandon et al. 2016) and has shown a low propensity for weight gain or metabolic disturbance in studies of adult patients (Loebel and Citrome 2015).

A pharmacokinetic study of single and multiple doses of lurasidone in children and adolescents (aged 6-17 years) with psychiatric disorders, including attention-deficit/hyperactivity disorder with conduct disorder, autism spectrum, bipolar spectrum, schizophrenia spectrum, or Tourette's syndrome, showed that lurasidone exposure in this heterogeneous pediatric population was generally similar to that observed in adult populations across the dose range of 20 to $160 \mathrm{mg} /$ day (Findling et al. 2015a). The adverse event profile suggested that lurasidone doses of $<120 \mathrm{mg} /$ day were better tolerated than higher doses.

This randomized, double-blind placebo-controlled study evaluated the efficacy and safety of lurasidone ( 40 and $80 \mathrm{mg} /$ day) in the acute treatment of adolescents (aged 13-17 years) with schizophrenia.

\section{Methods}

\section{Patients}

This study enrolled patients 13-17 years of age diagnosed with schizophrenia (based on Diagnostic and Statistical Manual of Mental Disorders, 4th Edition, Text Revision (DSM-IV-TR) criteria, confirmed with the Schedule for Affective Disorders and Schizophrenia for School-age Children [K-SADS-PL]) and experiencing acute exacerbation ( $\leq 2$ months in duration), as indicated by a Positive and Negative Symptom Scale (PANSS) total score $\geq 70$ and a Clinical Global Impressions-Severity (CGI-S) score $\geq 4$ (at least moderately ill). Key exclusion criteria were the presence of another DSM-IV diagnosis that had been the primary focus of treatment within the previous 3 months; a history or current diagnosis of intellectual disability or any neurologic disorder; clinically significant alcohol or substance abuse (previous 6 months); evidence of moderate or severe movement disorder; or imminent risk of suicide or injury to self or others. Additionally, patients were excluded if they demonstrated a decrease of $>25 \%$ in PANSS total score between screening and baseline or had a baseline PANSS total score $>120$ at screening or baseline.

The study was approved by an institutional review board or ethics committee at each investigational site and was conducted in accordance with the International Conference on Harmonization Good Clinical Practice guidelines and with the ethical principles of the
Declaration of Helsinki. After a full explanation of the study was provided, written informed consent was obtained from a parent or legal guardian and assent was obtained from each patient.

\section{Study design}

This multiregional, 6-week, randomized, double-blind, placebocontrolled parallel-group study was conducted between September 2013 and December 2015 at 72 clinical sites in 14 countries (United States, Ukraine, Russia, Bulgaria, Romania, Colombia, Mexico, Poland, Philippines, Korea, Malaysia, Spain, France, and Hungary). Patients were randomized in a 1:1:1 ratio through an interactive voice/ web response system to receive fixed-dose lurasidone $40 \mathrm{mg} /$ day, lurasidone $80 \mathrm{mg} /$ day, or placebo. Randomization was balanced using permuted blocks with stratification criteria for age group (13-15 and 16-17 years) and country. A central randomization center used a computer-generated list of random numbers to allocate study treatments. None of the investigators, study staff, or patients had access to the randomization codes or list.

Study medication was provided in blister packs of identically matched lurasidone $40 \mathrm{mg}$ or placebo tablets. Study medication (two tablets) was taken in the evening with a meal or within 30 minutes after eating. Patients assigned to lurasidone $40 \mathrm{mg}$ /day received that dose starting on day 1; patients assigned to lurasidone $80 \mathrm{mg} /$ day received $40 \mathrm{mg}$ /day for days $1-3$ and $80 \mathrm{mg} /$ day from day 4 onward. Assessment of adherence to study medication was based on tablet counts from returned blister packs at study visits. Adherence was calculated by dividing the number of doses missing by the number that should have been taken within a specified time period and multiplying by 100 . Patients who missed $>25 \%$ of scheduled doses or took $>125 \%$ of scheduled doses were considered nonadherent.

Hospitalization was permitted for part or all of the study. The decision to discharge from the hospital was made by the investigator based on the clinical stability of the patient, the availability of appropriate living arrangements, and caregiver support. A reliable informant (e.g., parent, legal guardian, or caregiver) was requested to accompany the patient to each study visit.

\section{Concomitant medications}

Patients were tapered off all psychotropic medications before randomization. Treatment with anticholinergic agents or propranolol was permitted for movement disorders as needed (but not prophylactically). Lorazepam, temazepam, and eszopiclone (or their equivalents) were permitted as needed for anxiety or insomnia, but not within 8 hours of any psychiatric assessment.

\section{Efficacy assessments}

The primary and key secondary efficacy endpoints were change from baseline to week 6 in PANSS total score (Kay et al. 1987) and CGI-S score (Guy 1976), respectively. Secondary efficacy assessments included the PANSS positive, negative, general psychopathology, and excitability subscale scores; the Pediatric Quality of Life Enjoyment and Satisfaction Questionnaire (Endicott et al. 2006); and the clinician-rated Children's Global Assessment Scale (a measure of functional impairment) (Shaffer et al. 1983). Efficacy and safety assessments were performed by qualified site-based raters who had completed a rater training program.

\section{Safety and tolerability evaluation}

Safety and tolerability were assessed by the incidence and severity of adverse events during the study. Adverse event reporting 
was supplemented by administration of the Udvalg for Kliniske Undersogelser (UKU) Side Effect Rating Scale, a clinician-rated scale of 48 adverse event items divided into four categories (psychic, neurologic, autonomic, and other) (Lingjaerde et al. 1987). Movement disorders were assessed by the Simpson-Angus Scale (Simpson and Angus 1970), the Barnes Akathisia Rating Scale (Barnes 1989), and the Abnormal Involuntary Movement Scale (Guy 1976; Munetz and Benjamin 1988). Effects of treatment on cognitive function were evaluated with the Cogstate brief battery, which consists of four computerized tests assessing four distinct cognitive domains (psychomotor speed, attention, learning/memory, and working memory) (Maruff et al. 2009). The Columbia Suicide Severity Rating Scale (Posner et al. 2011) was used to assess suicidal ideation and behavior. Additional safety evaluations included vital signs, weight, age- and gender-adjusted body mass index (BMI), laboratory tests, 12-lead electrocardiogram, and physical examination.

\section{Statistical analysis}

The intent-to-treat (ITT) population consisted of randomly assigned patients who received at least one dose of study medication and had a least one postbaseline efficacy assessment. PANSS and CGI-S efficacy endpoints were evaluated using a likelihood-based mixed model for repeated measurement (MMRM) analysis with fixed effect terms for treatment, visit (as a categorical variable), pooled country, age group, baseline PANSS total score, and treatment-by-visit interaction term, using an unstructured covariance model for within-patient correlation. A truncated Hochberg-based gatekeeping procedure with a predefined truncation parameter of 0.5 was applied to control the familywise type I error rate at $5 \%$ (two-sided) by taking into account the primary and key secondary efficacy variables and multiple dose comparisons of lurasidone versus placebo (Dmitrienko et al. 2011). There was no multiplicity adjustment for the secondary efficacy analyses or safety analyses. Change from baseline in PANSS subscale scores was evaluated using MMRM analysis. Change from baseline in the Pediatric Quality of Life Enjoyment and Satisfaction Questionnaire and the Children's Global Assessment Scale (which were administered only at baseline and week 6) was evaluated using an analysis of covariance (ANCOVA) model adjusting for treatment, pooled country, and age group, with corresponding baseline scores as a covariate, using a last observation carried forward (LOCF) approach.

Treatment response was defined as $\geq 20 \%$ reduction in PANSS total score from baseline to week 6 (LOCF), with 30 points subtracted from the PANSS total score to account for the scale range. Remission was defined as a score $\leq 3$ (mild severity) on the PANSS items of delusions, conceptual disorganization, hallucinatory behavior, blunted affect, passive social withdrawal, lack of spontaneity, mannerisms and posturing, and unusual thought content at week 6 (LOCF) (Andreasen et al. 2005). The proportion of responders and remitters was compared for lurasidone versus placebo using a logistic regression model adjusting for treatment, pooled country, and age group, with baseline PANSS total score as a covariate. The number needed to treat (NNT) to attain one additional responder/ remitter was derived for the lurasidone groups as follows: $\mathrm{NNT}=1$ / (lurasidone response rate-placebo response rate).

The safety population consisted of patients who were randomly assigned to treatment and received at least one dose of study medication. Descriptive statistics were used for safety variables, including adverse events, vital signs, and laboratory results. In addition, MMRM analysis was used to evaluate change from baseline in body weight, ANCOVA was used to evaluate age- and gender-adjusted body-mass index (BMI) z-score per WHO 2007 reference growth charts, and nonparametric rank ANCOVA was used to analyze laboratory parameters. Change from baseline (LOCF) in the Cogstate brief battery cognitive composite standardized score and the Simpson-Angus Scale, Barnes Akathisia Rating Scale, and Abnormal Involuntary Movement Scale scores were analyzed using ANCOVA with terms for treatment, pooled country, and age group, and baseline score as a covariate. The Cogstate brief battery cognitive composite standardized score was calculated as the average of the standardized scores of detection task (speed component), identification task (speed component), one back task (speed component), and one card learning task (accuracy component); each of these individual standardized scores was adjusted by age (in years) as per normative data provided by Cogstate from healthy children and adolescents.

Sample size was determined based on the results of a Monte Carlo simulation. Dunnett's method was used to adjust for the multiple comparisons of two lurasidone doses versus placebo. To detect a 6-point difference for lurasidone $40 \mathrm{mg}$ /day versus placebo (standard deviation $[\mathrm{SD}]=18$; effect size $=0.333$ ) and an 8.5-point difference for lurasidone $80 \mathrm{mg} /$ day versus placebo $(\mathrm{SD}=18$; effect size $=0.472$ ) in mean change from baseline to week 6 in PANSS total score, a total sample of $\sim 309$ patients (103 patients per group) would be required to provide $85 \%$ power to reject at least one of the null hypotheses, assuming an attrition rate of $15 \%$.

\section{Results}

A total of 380 patients were screened, of whom, 326 patients met all eligibility criteria, were randomly assigned to double-blind treatment, and received at least one dose of study medication: lurasidone $40 \mathrm{mg} /$ day $(N=108)$, lurasidone $80 \mathrm{mg} /$ day $(N=106)$, or placebo $(N=112)$ (Fig. 1). Of the 53 patients who were screen failures, the majority $(n=40)$ failed to meet inclusion criteria, while 10 withdrew consent.

Demographic and clinical characteristics were similar for the three treatment groups randomized at study baseline (Table 1). The rate of study discontinuation was greater in patients randomly assigned to placebo $(17.7 \%)$ compared with lurasidone $40 \mathrm{mg} /$ day $(11.1 \%)$ or lurasidone $80 \mathrm{mg} /$ day $(9.4 \%)$. Discontinuation due to adverse events occurred in $4.6 \%$ of patients in the lurasidone $40 \mathrm{mg}$ /day group, $2.8 \%$ of patients in the lurasidone $80 \mathrm{mg} /$ day group, and $8.0 \%$ of patients in the placebo group. Discontinuation for insufficient clinical response was noted in $0.9 \%$ of patients in the lurasidone $40 \mathrm{mg}$ /day group, $1.9 \%$ of patients in the lurasidone $80 \mathrm{mg} /$ day group, and $3.5 \%$ of patients in the placebo group. The adverse event that most commonly led to treatment discontinuation was schizophrenia worsening (1.8\% of patients in the lurasidone $40 \mathrm{mg} /$ day group, $1.0 \%$ of patients in the lurasidone $80 \mathrm{mg} /$ day group, and $5.4 \%$ of patients in the placebo group). All other adverse events leading to discontinuation in lurasidonetreated patients (anxiety, homicidal ideation, hypersensitivity, irritability, and suicidal ideation) were limited to a single patient each.

Rate of treatment adherence for the overall double-blind treatment period (assessed by returned tablet count) was high in all groups: $100.0 \%$ in the lurasidone $80 \mathrm{mg} /$ day group, $99.0 \%$ in the lurasidone $40 \mathrm{mg} /$ day group, and $97.3 \%$ in the placebo group (adherence data were not available for 11 patients due to at least one nonreturned dispensed kit).

\section{Efficacy}

The least-squares (LS) mean change from baseline to week 6 in PANSS total score (primary endpoint) was significantly greater for the lurasidone $40 \mathrm{mg} /$ day group $(-18.6 ; p<0.001$; effect size $=$ $0.51)$ and the lurasidone $80 \mathrm{mg} /$ day group $(-18.3 ; p<0.001$; effect 


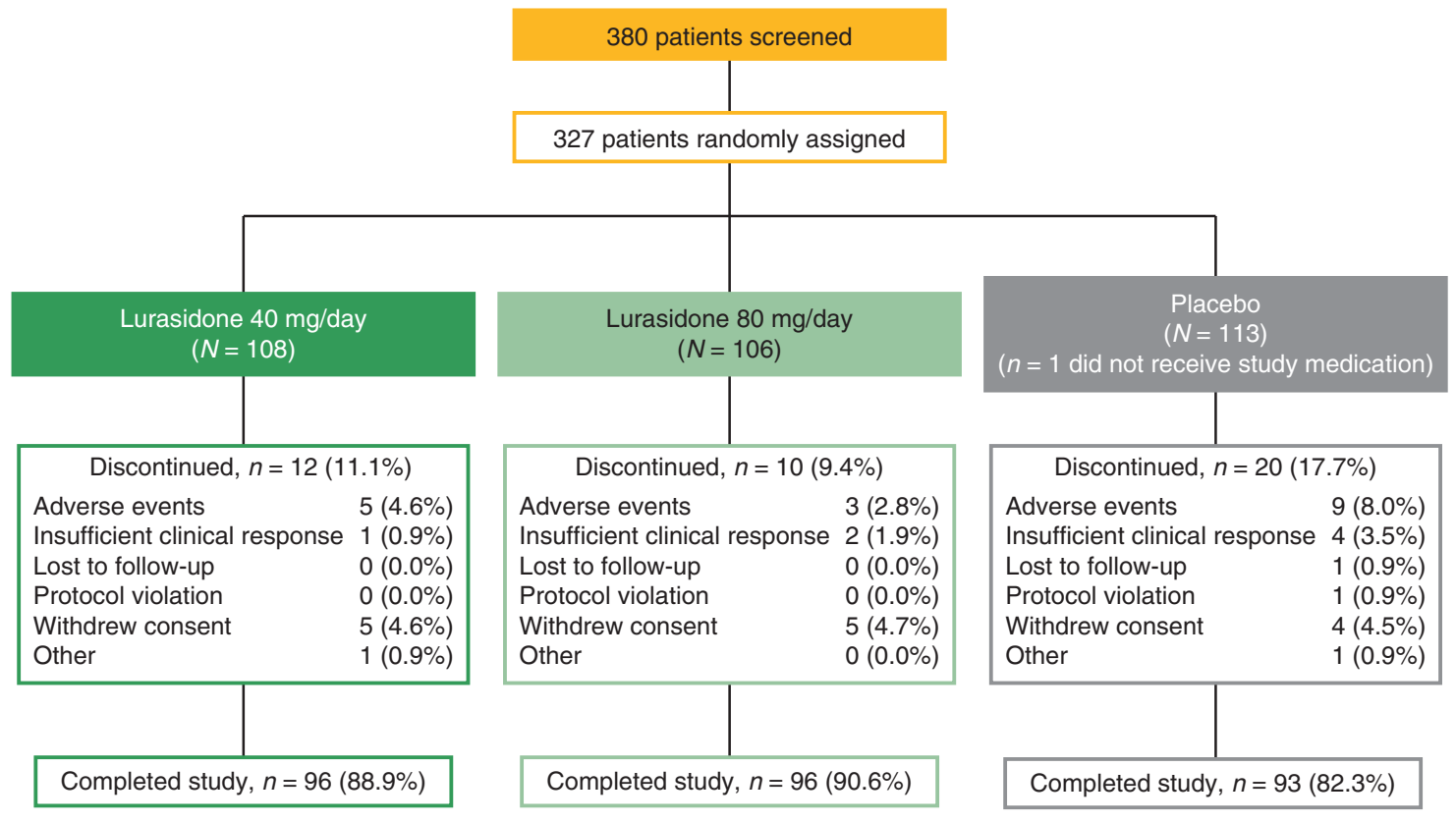

FIG. 1. Patient disposition for adolescents with schizophrenia enrolled in a 6-week, randomized, double-blind placebo-controlled study of lurasidone.

size $=0.48)$ compared with the placebo group $(-10.5)$. Both the lurasidone 40 and $80 \mathrm{mg} /$ day treatment groups demonstrated significant separation from placebo on the PANSS total score starting at week 1 ( $p=0.02$ and $p=0.03$, respectively) and at all subsequent visits (Fig. 2A).
Improvement in PANSS total score from baseline to week 6 (LOCF) was similar in patients 13-15 years old (LS mean change of -18.0 in the lurasidone $40 \mathrm{mg} /$ day group, -17.8 in the lurasidone $80 \mathrm{mg} /$ day group, and -10.1 in the placebo group) and patients 16-17 years old (LS mean change of -16.2 in the lurasidone $40 \mathrm{mg}$ /

Table 1. Demographic and Clinical Characteristics at Baseline in Adolescents with Schizophrenia (Intent-to-Treat Population)

\begin{tabular}{|c|c|c|c|}
\hline Characteristic & $\begin{array}{l}\text { Lurasidone } 40 \mathrm{mg} / \text { day } \\
\qquad(\mathrm{N}=108)\end{array}$ & $\begin{array}{l}\text { Lurasidone } 80 \mathrm{mg} / \text { day } \\
\qquad(\mathrm{N}=106)\end{array}$ & $\begin{array}{l}\text { Placebo } \\
(\mathrm{N}=112)\end{array}$ \\
\hline Age, years, mean (SD) & $15.5(1.3)$ & $15.3(1.4)$ & $15.3(1.4)$ \\
\hline \multicolumn{4}{|l|}{ Age category, $n(\%)$} \\
\hline $13-15$ years & $50(46.3)$ & $55(51.9)$ & $55(49.1)$ \\
\hline 16-17 years & $58(53.7)$ & $51(48.1)$ & $57(50.9)$ \\
\hline Male, $n(\%)$ & $67(62.0)$ & $70(66.0)$ & $71(63.4)$ \\
\hline \multicolumn{4}{|l|}{ Race, $n(\%)$} \\
\hline White & $72(66.7)$ & $74(69.8)$ & $74(66.1)$ \\
\hline Black & 19 (17.6) & $19(17.9)$ & $22(19.6)$ \\
\hline Asian & $6(5.6)$ & $4(3.8)$ & $5(4.5)$ \\
\hline Other & $11(10.2)$ & $9(8.5)$ & $11(9.8)$ \\
\hline Hispanic/Latino ethnicity, $n(\%)$ & $12(11.1)$ & 19 (17.9) & $13(11.6)$ \\
\hline Weight, $\mathrm{kg}$, mean (SD) & $63.6(12.4)$ & $638(12.9)$ & $64.0(11.9)$ \\
\hline $\mathrm{BMI}, \mathrm{kg} / \mathrm{m}^{2}$, mean $(\mathrm{SD})$ & $22.4(3.3)$ & $22.6(3.5)$ & $22.5(3.6)$ \\
\hline BMI percentile, mean (SD) ${ }^{\mathrm{a}}$ & $63.2(28.4)$ & $66.1(27.9)$ & $64.4(30.1)$ \\
\hline \multicolumn{4}{|l|}{$D S M-I V$-TR diagnosis, $n(\%)$} \\
\hline Paranoid (295.30) & $86(79.6)$ & $83(78.3)$ & $85(75.9)$ \\
\hline Disorganized (295.10) & $13(12.0)$ & $6(5.7)$ & $7(6.3)$ \\
\hline Undifferentiated (295.90) & $9(8.3)$ & $17(16.0)$ & $20(17.9)$ \\
\hline Age at psychosis symptom onset, years, mean (SD) & $13.4(2.7)$ & $12.9(2.9)$ & $13.1(2.7)$ \\
\hline$\geq 1$ prior hospitalizations, $n(\%)$ & $56(51.9)$ & $56(52.8)$ & $61(54.5)$ \\
\hline Prior antipsychotic medication use, $n(\%)$ & $86(79.6)$ & $89(84.0)$ & $94(83.9)$ \\
\hline PANSS total score, mean (SD) & $94.5(11.0)$ & $94.0(11.1)$ & $92.8(11.1)$ \\
\hline CGI-S score, mean (SD) & $4.9(0.6)$ & $4.8(0.7)$ & $4.8(0.6)$ \\
\hline
\end{tabular}

${ }^{\mathrm{a}}$ As per World Health Organization 2007 reference growth charts.

BMI, body mass index; CGI-S, Clinical Global Impressions-Severity; DSM-IV-TR, Diagnostic and Statistical Manual of Mental Disorders, 4th Edition, Text Revision; PANSS, Positive and Negative Syndrome Scale; SD, standard deviation. 

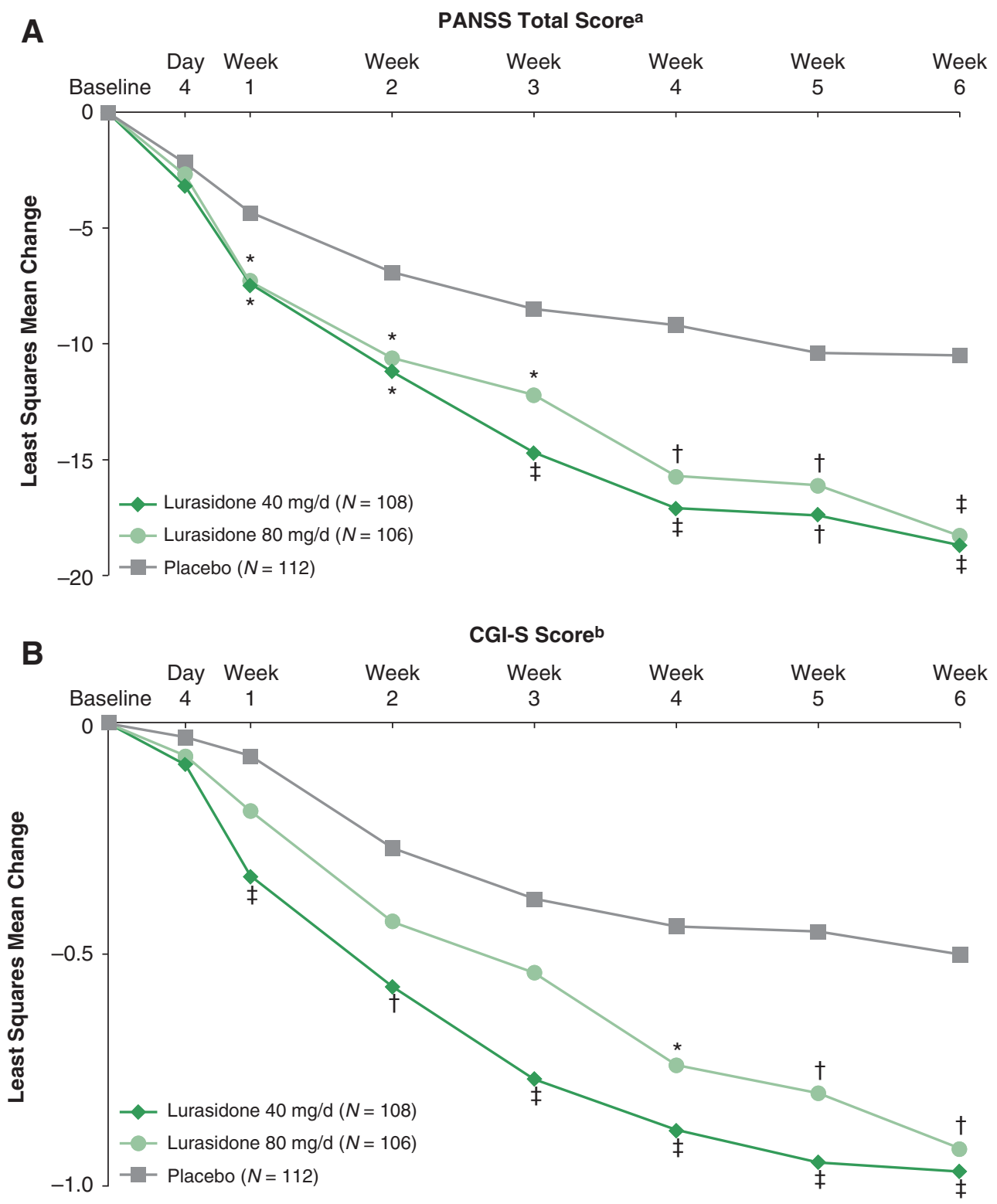

FIG. 2. Least-squares mean change in (A) PANSS total score ${ }^{\mathrm{a}}$ and (B) CGI-S score ${ }^{\mathrm{b}}$ from baseline through week 6 in adolescents with schizophrenia treated with lurasidone $40 \mathrm{mg}$ /day, lurasidone $80 \mathrm{mg} / \mathrm{day}$, or placebo (MMRM analysis, ITT population). ${ }^{\mathrm{a}} \mathrm{Mean}$ (SD) scores at baseline were 94.5 (11.0), 94.0 (11.1), and 92.8 (11.1) for the lurasidone $40 \mathrm{mg} /$ day, lurasidone $80 \mathrm{mg} /$ day, and placebo groups, respectively. ${ }^{b}$ Mean (SD) scores at baseline were $4.9(0.6), 4.8(0.7)$, and $4.8(0.6)$ for the lurasidone $40 \mathrm{mg} / \mathrm{day}$, lurasidone $80 \mathrm{mg} / \mathrm{day}$, and placebo groups, respectively. ${ }^{*} p<0.05 ;{ }^{\dagger} p<0.01 ;{ }^{\star} p<0.001$ versus placebo. CGI-S, Clinical Global Impressions-Severity; ITT, intent-to-treat; MMRM, mixed model for repeated measurement; PANSS, Positive and Negative Syndrome Scale; SD, standard deviation.

day group, -15.7 in the lurasidone $80 \mathrm{mg} /$ day group, and -7.7 in the placebo group). The LS mean change from baseline to week 6 in CGI-S score (key secondary endpoint) was significantly greater for the lurasidone $40 \mathrm{mg} /$ day group $(-1.0 ; p<0.001$; effect size $=0.49)$ and the lurasidone $80 \mathrm{mg} /$ day group $(-0.9 ; p=0.0015$; effect size $=0.45)$ compared with the placebo group $(-0.5)$. Significant differences from placebo on the CGI-S were observed starting at week 1 for the lurasidone $40 \mathrm{mg} /$ day group and at week 4 for the lurasidone $80 \mathrm{mg} /$ day group and were maintained at all subsequent study visits (Fig. 2B).

A significantly greater proportion of patients met a priori response criteria after 6 weeks of treatment (LOCF) with lurasidone $40 \mathrm{mg} /$ day $(63.9 \% ; p<0.001 ; \mathrm{NNT}=5)$ and lurasidone $80 \mathrm{mg} / \mathrm{day}$
$(65.1 \% ; p<0.001 ; \mathrm{NNT}=5)$ compared with placebo $(42.0 \%)$. The proportion of patients achieving remission at week 6 (LOCF) was $36.1 \%$ in the lurasidone $40 \mathrm{mg} /$ day group $(p=0.138)$ and $35.8 \%$ in the lurasidone $80 \mathrm{mg} /$ day group $(p=0.213)$ compared with $29.5 \%$ in the placebo group. Both lurasidone treatment groups demonstrated significant improvement compared with placebo on the PANSS subscales (positive symptoms, negative symptoms, general psychopathology, and excitability), the patient-reported Pediatric Quality of Life Enjoyment and Satisfaction Questionnaire, and the clinician-rated Children's Global Assessment Scale (Table 2). Effect sizes at week 6 (LOCF) were 0.45 in the lurasidone $40 \mathrm{mg} /$ day group and 0.49 in the lurasidone $80 \mathrm{mg} /$ day group on the Pediatric Quality of Life Enjoyment and Satisfaction 
Table 2. Efficacy Measures in Adolescents with Schizophrenia Treated with Lurasidone (40 or 80 mg/Day) or Placebo for 6 Weeks (Intent-to-Treat Population)

\begin{tabular}{|c|c|c|c|c|c|c|}
\hline \multirow[b]{2}{*}{ Measure } & \multicolumn{2}{|c|}{$\begin{array}{c}\text { Lurasidone } \\
40 \mathrm{mg} / \text { day }(\mathrm{N}=110)\end{array}$} & \multicolumn{2}{|c|}{$\begin{array}{c}\text { Lurasidone } \\
80 \mathrm{mg} / \text { day }(\mathrm{N}=104)\end{array}$} & \multicolumn{2}{|c|}{$\begin{array}{l}\text { Placebo } \\
(\mathrm{N}=112)\end{array}$} \\
\hline & $M e a n^{\mathrm{a}}$ & $S E^{\mathrm{b}}$ & $M e a n^{\mathrm{a}}$ & $S E^{\mathrm{b}}$ & Mean $^{\mathrm{a}}$ & $\mathrm{SE}^{\mathrm{b}}$ \\
\hline \multicolumn{7}{|l|}{ PANSS total } \\
\hline Baseline & 94.5 & 11.0 & 94.0 & 11.1 & 92.8 & 11.1 \\
\hline Change at week 6 (MMRM) & $-18.6^{\mathrm{c}}$ & 1.6 & $-18.3^{\mathrm{c}}$ & 1.6 & -10.5 & 1.6 \\
\hline \multicolumn{7}{|l|}{ PANSS positive } \\
\hline Baseline & 24.1 & 4.0 & 24.0 & 4.1 & 23.4 & 3.8 \\
\hline Change at week 6 (MMRM) & $-6.3^{\mathrm{c}}$ & 0.5 & $-6.3^{\mathrm{c}}$ & 0.5 & -3.1 & 0.5 \\
\hline \multicolumn{7}{|l|}{ PANSS negative } \\
\hline Baseline & 24.2 & 4.3 & 24.5 & 4.4 & 24.4 & 4.0 \\
\hline Change at week 6 (MMRM) & $-4.0^{\mathrm{d}}$ & 0.5 & $-3.8^{\mathrm{d}}$ & 0.5 & -2.3 & 0.5 \\
\hline \multicolumn{7}{|l|}{ PANSS general psychopathology } \\
\hline Baseline & 46.2 & 6.7 & 45.5 & 7.0 & 45.0 & 6.9 \\
\hline Change at week 6 (MMRM) & $-8.1^{\mathrm{d}}$ & 0.8 & $-8.1^{\mathrm{d}}$ & 0.8 & -5.3 & 0.8 \\
\hline \multicolumn{7}{|l|}{ PANSS excitability } \\
\hline Baseline & 10.8 & 2.9 & 11.1 & 3.1 & 10.7 & 3.2 \\
\hline Change at week 6 (MMRM) & $-1.7^{\mathrm{d}}$ & 0.3 & $-2.4^{\mathrm{c}}$ & 0.3 & -0.6 & 0.3 \\
\hline \multicolumn{7}{|l|}{ CGI-S } \\
\hline Baseline & 4.9 & 0.6 & 4.8 & 0.7 & 4.8 & 0.6 \\
\hline Change at week 6 (MMRM) & $-1.0^{\mathrm{c}}$ & 0.1 & $-0.9^{\mathrm{e}}$ & 0.1 & -0.5 & 0.1 \\
\hline \multicolumn{7}{|l|}{ PQ-LES-Q } \\
\hline Baseline & 51.3 & 17.3 & 53.6 & 18.5 & 52.5 & 15.7 \\
\hline Change at week 6 (ANCOVA $)^{\mathrm{f}}$ & $5.5^{\mathrm{d}}$ & 1.3 & $6.8^{\mathrm{c}}$ & 1.3 & 1.4 & 1.3 \\
\hline \multicolumn{7}{|l|}{ CGAS } \\
\hline Baseline & 44.2 & 9.3 & 44.6 & 8.1 & 43.9 & 8.3 \\
\hline Change at week 6 (ANCOVA $)^{\mathrm{f}}$ & $10.7^{\mathrm{e}}$ & 1.1 & $11.0^{\mathrm{c}}$ & 1.2 & 6.1 & 1.1 \\
\hline Treatment responders at week $6^{\mathrm{g}}, \%$ & \multicolumn{2}{|c|}{$63.9^{\mathrm{c}}$} & \multicolumn{2}{|c|}{$65.1^{\mathrm{c}}$} & \multicolumn{2}{|c|}{42.0} \\
\hline Remitters at week $6^{\mathrm{h}}, \%$ & \multicolumn{2}{|c|}{36.1} & \multicolumn{2}{|c|}{35.8} & \multicolumn{2}{|c|}{29.5} \\
\hline
\end{tabular}

Two patients randomly assigned to lurasidone $80 \mathrm{mg} /$ day discontinued study participation while receiving lurasidone $40 \mathrm{mg} / \mathrm{day}$ as part of the planned titration procedure; they were included in the lurasidone $80 \mathrm{mg} /$ day group (as randomized) for efficacy analyses and the lurasidone $40 \mathrm{mg} / \mathrm{day}$ group (actual dose received) for safety analyses.

${ }^{\mathrm{a}}$ Means are shown for baseline scores, LS means are shown for change at week 6.

${ }^{\mathrm{b}} \mathrm{Standard}$ deviation is shown for baseline scores; standard error is shown for change at week 6.

${ }^{\mathrm{c}} P<0.001$ versus placebo.

${ }^{\mathrm{d}} P<0.05$ versus placebo.

${ }^{\mathrm{e}} P<0.01$ versus placebo.

${ }^{\mathrm{f}}$ Based on analysis of covariance.

${ }^{\mathrm{g}}$ Treatment response was defined as $\geq 20 \%$ reduction in PANSS total score from baseline to week 6 (LOCF), with 30 points subtracted from the PANSS total score to account for the scale range.

${ }^{\mathrm{h}}$ Remission was defined as a score $\leq 3$ (mild severity) on the PANSS items of delusions, conceptual disorganization, hallucinatory behavior, blunted affect, passive social withdrawal, lack of spontaneity, mannerisms and posturing, and unusual thought content at week 6 (LOCF).

CGAS, Children's Global Assessment Scale; CGI-S, Clinical Global Impressions-Severity; LOCF, last observation carried forward; LS, least-squares; MMRM, mixed model for repeated measurement; PANSS, Positive and Negative Syndrome Scale; PQ-LES-Q, Pediatric Quality of Life Enjoyment and Satisfaction Questionnaire; SE, standard error.

Questionnaire and 0.43 and 0.46 , respectively, on the Children's Global Assessment Scale.

\section{Safety}

Adverse events with incidence $\geq 5 \%$ in either lurasidone dose group are listed in Table 3 . The majority of adverse events were reported as mild or moderate in severity, with adverse events rated as severe in $5.5 \%$ of patients in the lurasidone $40 \mathrm{mg}$ /day group, $5.4 \%$ of patients in the placebo group, and no patients in the lurasidone $80 \mathrm{mg} /$ day group. The incidence of serious adverse events was lower in the lurasidone $40 \mathrm{mg} /$ day (3.6\%) and lurasidone $80 \mathrm{mg} /$ day (1.9\%) groups compared with placebo $(8.0 \%)$. No deaths occurred during the study. The incidence of adverse events in lurasidone-treated patients overall was similar for patients $13-15$ years old $(67.6 \%)$ and $16-17$ years old $(60.6 \%)$, as was the incidence of serious adverse events (3.8\% and $1.8 \%$, respectively).

Change from baseline to endpoint in the four UKU side effect categories (psychic, neurologic, autonomic, and other) was generally similar between the two lurasidone dose groups and the placebo group (Table 4). The proportion of patients with treatment-emergent suicidal ideation, as per the Columbia Suicide Severity Rating Scale, was $5.5 \%$ in the lurasidone $40 \mathrm{mg}$ /day group, $4.5 \%$ in the placebo group, and $1.0 \%$ in the lurasidone $80 \mathrm{mg}$ /day group. One patient in the lurasidone $40 \mathrm{mg} /$ day group discontinued from the study due to suicidal ideation. There was no occurrence of suicidal behavior or completed suicide during the study. 
Table 3. Adverse Events (Incidence $\geq 5 \%$ in Either Lurasidone Group) in Adolescents with Schizophrenia Treated with Lurasidone 40 mg/Day, Lurasidone 80 mg/Day, or Placebo (Safety Population)

\begin{tabular}{lccc}
\hline Adverse event, $\mathrm{n}(\%)$ & Lurasidone $40 \mathrm{mg} /$ day $(\mathrm{N}=110)$ & Lurasidone $80 \mathrm{mg} /$ day $(\mathrm{N}=104)$ & Placebo $(\mathrm{N}=112)$ \\
\hline At least one event & $70(63.6)$ & $67(64.4)$ & $64(57.1)$ \\
Nausea & $14(12.7)$ & $15(14.4)$ & $3(2.7)$ \\
Anxiety & $11(10.0)$ & $3(2.9)$ & $9(8.0)$ \\
Akathisia & $10(9.1)$ & $9(8.7)$ & $2(1.8)$ \\
Somnolence & $10(9.1)$ & $12(11.5)$ & $6(5.4)$ \\
Vomiting & $9(8.2)$ & $7(6.7)$ & $2(1.8)$ \\
Headache & $7(6.4)$ & $11(10.6)$ & $14(12.5)$ \\
Insomnia & $6(5.5)$ & $7(6.7)$ & $10(8.9)$ \\
Sedation & $6(5.5)$ & $2(1.9)$ & $2(1.8)$ \\
Agitation & $5(4.5)$ & $6(5.8)$ & $5(4.5)$ \\
Extrapyramidal events & & $4(3.8)$ & $2(1.8)$ \\
\hline
\end{tabular}

Two patients randomly assigned to lurasidone $80 \mathrm{mg} /$ day discontinued study participation while receiving lurasidone $40 \mathrm{mg} / \mathrm{day}$ as part of the planned titration procedure; they were included in the lurasidone $80 \mathrm{mg} / \mathrm{day}$ group (as randomized) for efficacy analyses and the lurasidone $40 \mathrm{mg} / \mathrm{day}$ group (actual dose received) for safety analyses.

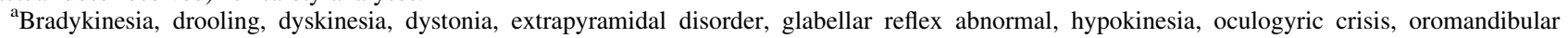
dystonia, parkinsonism, psychomotor retardation, salivary hypersecretion, tardive dyskinesia, tongue spasm, torticollis, or trismus.

The incidence of extrapyramidal symptom-related adverse events (excluding akathisia) was $6.4 \%$ in the lurasidone $40 \mathrm{mg} /$ day group, $3.8 \%$ in the lurasidone $80 \mathrm{mg} /$ day group, and $1.8 \%$ in the placebo group (Table 3). The incidence of akathisia was $9.1 \%$ in the lurasidone $40 \mathrm{mg} /$ day group, $8.7 \%$ in the lurasidone $80 \mathrm{mg} /$ day group, and $1.8 \%$ in the placebo group. One patient (receiving lurasidone $40 \mathrm{mg} /$ day) experienced akathisia rated as severe; akathisia was otherwise rated as mild (eight patients receiving lurasidone $40 \mathrm{mg} /$ day and five patients receiving lurasidone $80 \mathrm{mg} /$ day) or moderate (one patient receiving lurasidone $40 \mathrm{mg} /$ day group, four patients receiving lurasidone $80 \mathrm{mg} /$ day, and two patients receiving placebo) in severity. The proportion of patients who received treatment with anticholinergic medications for acute extrapyramidal symptoms was $4.5 \%$ in the lurasidone $40 \mathrm{mg} /$ day group, $2.9 \%$ in the lurasidone $80 \mathrm{mg} /$ day group, and $1.8 \%$ in the placebo group. LS mean changes from baseline to endpoint (lurasidone 40 and $80 \mathrm{mg} /$ day vs. placebo) were small and not clinically meaningful for the Simpson-Angus Scale (0.01 and 0.02 vs. 0.01), Barnes Akathisia Rating Scale (0.16 and 0.16 vs. 0.07), and Abnormal Involuntary Movement Scale (0.04 and 0.08 vs. -0.02). There was one study discontinuation due to a movement disorder: a patient in the placebo group with akathisia.

There were no clinically meaningful treatment differences between lurasidone and placebo groups on laboratory measures of lipid parameters, glycemic indices, and prolactin levels (Table 5). LS mean change in body weight to week 6 (MMRM analysis) and BMI z-score (ANCOVA) was not different for the lurasidone $40 \mathrm{mg} /$ day group $(0.17 \mathrm{~kg}$ and -0.02 , respectively) or lurasidone $80 \mathrm{mg} /$ day group $(0.49 \mathrm{~kg}$ and 0.00 , respectively) compared with the placebo group $(0.05 \mathrm{~kg}$ and -0.03 , respectively $)$. The proportion of patients with clinically meaningful weight gain $(\geq 7 \%)$

Table 4. Change From Baseline at Endpoint in Udvalg for Kliniske Undersogelser Side Effect Rating Scale Scores in Adolescents with Schizophrenia Treated with Lurasidone 40 mg/Day, 80 mg/Day, or Placebo (Safety Population)

\begin{tabular}{|c|c|c|c|}
\hline$U K U$ category & Lurasidone $40 \mathrm{mg} /$ day $(\mathrm{N}=105)$ & Lurasidone $80 \mathrm{mg} /$ day $(\mathrm{N}=102)$ & Placebo $(\mathrm{N}=103)$ \\
\hline \multicolumn{4}{|l|}{ Psychic side effects } \\
\hline Baseline, mean (SD) & $4.2(4.4)$ & $4.5(3.9)$ & $4.3(4.0)$ \\
\hline Change from baseline, mean (SD) & $-1.3(3.3)$ & $-1.2(2.8)$ & $-0.9(3.3)$ \\
\hline \multicolumn{4}{|l|}{ Neurologic side effects } \\
\hline Baseline, mean (SD) & $0.3(0.8)$ & $0.2(0.6)$ & $0.3(0.7)$ \\
\hline Change from baseline, mean (SD) & $-0.1(0.8)$ & $0.0(0.7)$ & $-0.1(0.7)$ \\
\hline \multicolumn{4}{|l|}{ Autonomic side effects } \\
\hline Baseline, mean (SD) & $0.4(0.9)$ & $0.3(0.7)$ & $0.3(1.1)$ \\
\hline Change from baseline, mean (SD) & $-0.2(1.0)$ & $0.0(0.8)$ & $-0.1(1.0)$ \\
\hline \multicolumn{4}{|l|}{ Other side effects } \\
\hline Baseline, mean (SD) & $0.4(0.9)$ & $0.3(1.0)$ & $0.3(0.8)$ \\
\hline Change from baseline, mean (SD) & $0.0(0.9)$ & $0.2(0.8)$ & $0.1(0.8)$ \\
\hline \multicolumn{4}{|l|}{ UKU total score } \\
\hline Baseline, mean (SD) & $5.2(5.4)$ & $5.3(4.6)$ & $5.2(5.0)$ \\
\hline Change from baseline, mean (SD) & $-1.5(4.4)$ & $-1.0(3.4)$ & $-1.0(3.9)$ \\
\hline
\end{tabular}

Higher scores indicate greater severity; range of 0-30 for psychic, 0-24 for neurologic, 0-33 for autonomic, and 0-48 for other. Two patients randomly assigned to lurasidone $80 \mathrm{mg} / \mathrm{day}$ discontinued study participation while receiving lurasidone $40 \mathrm{mg} / \mathrm{day}$ as part of the planned titration procedure; they were included in the lurasidone $80 \mathrm{mg} /$ day group (as randomized) for efficacy analyses and the lurasidone $40 \mathrm{mg} / \mathrm{day}$ group (actual dose received) for safety analyses.

SD, standard deviation; UKU, Udvalg for Kliniske Undersogelser. 
Table 5. Baseline to Endpoint Change in Weight, Body Mass Index, and Selected Laboratory Parameters in Adolescents with Schizophrenia Treated with Lurasidone 40 Mg/Day, 80 Mg/Day, or Placebo (Last Observation Carried Forward; Safety Population)

\begin{tabular}{|c|c|c|c|c|c|c|}
\hline \multirow[b]{2}{*}{ Measure $^{\mathrm{a}}$} & \multicolumn{2}{|c|}{ Lurasidone $40 \mathrm{mg} /$ day $(\mathrm{N}=110)$} & \multicolumn{2}{|c|}{ Lurasidone $80 \mathrm{mg} /$ day $(\mathrm{N}=104)$} & \multicolumn{2}{|c|}{ Placebo $(\mathrm{N}=112)$} \\
\hline & \multicolumn{2}{|c|}{$L S$ mean $(S E)$} & \multicolumn{2}{|c|}{$L S$ mean $(S E)$} & \multicolumn{2}{|c|}{$L S$ mean $(S E)$} \\
\hline Weight, $\mathrm{kg}^{\mathrm{b}}$ & \multirow{2}{*}{\multicolumn{2}{|c|}{$\begin{array}{c}0.17(0.2) \\
-0.02(0.03)\end{array}$}} & \multirow{2}{*}{\multicolumn{2}{|c|}{$\begin{array}{c}0.49(0.2) \\
0.00(0.03)\end{array}$}} & \multirow{2}{*}{\multicolumn{2}{|c|}{$\begin{array}{c}0.05(0.2) \\
-0.03(0.03)\end{array}$}} \\
\hline Body mass index, $\mathrm{z}$-score ${ }^{\mathrm{c}}$ & & & & & & \\
\hline & Mean (SD) & Median & Mean (SD) & Median & Mean (SD) & Median \\
\hline Total cholesterol, mg/dL & $-5.2(24.9)$ & -4.0 & $1.0(29.3)$ & -2.0 & $-8.2(23.9)$ & -7.0 \\
\hline LDL cholesterol, $\mathrm{mg} / \mathrm{dL}$ & $-4.4(19.9)$ & -3.5 & $0.6(24.9)$ & 0.0 & $-5.1(19.5)$ & -4.0 \\
\hline Triglycerides, $\mathrm{mg} / \mathrm{dL}$ & $-6.1(62.4)$ & -2.0 & $8.7(55.6)$ & 7.0 & $0.8(51.2)$ & -2.0 \\
\hline Glucose, $\mathrm{mg} / \mathrm{dL}$ & $-0.3(11.1)$ & 0.0 & 0.8 (11.6) & 1.0 & $-0.3(14.1)$ & 0.0 \\
\hline $\mathrm{HbA}_{1 \mathrm{c}}, \%$ & $0.0(0.2)$ & 0.0 & $0.0(0.2)$ & 0.0 & $0.0(0.2)$ & 0.0 \\
\hline Insulin, mU/L & $-4.6(46.0)$ & -0.4 & $2.6(26.0)$ & 0.1 & $-3.6(51.6)$ & -0.3 \\
\hline \multicolumn{7}{|l|}{ Prolactin, ng/mL } \\
\hline Males & $-0.1(11.1)$ & 0.8 & $2.1(15.0)$ & 1.0 & $0.1(22.0)$ & 0.0 \\
\hline Females & $2.4(35.3)$ & 0.6 & $7.9(14.4)$ & 4.4 & $-2.3(22.8)$ & 0.7 \\
\hline
\end{tabular}

Two patients randomly assigned to lurasidone $80 \mathrm{mg} /$ day discontinued study participation while receiving lurasidone $40 \mathrm{mg} / \mathrm{day}$ as part of the planned titration procedure; they were included in the lurasidone $80 \mathrm{mg} /$ day group (as randomized) for efficacy analyses and the lurasidone $40 \mathrm{mg} / \mathrm{day}$ group (actual dose received) for safety analyses.

${ }^{\text {a} B o t h ~ c o n f i r m e d ~ a n d ~ n o n c o n f i r m e d ~ f a s t i n g ~ v a l u e s ~ a r e ~ p r e s e n t e d ~ f o r ~ m e t a b o l i c ~ p a r a m e t e r s . ~}$

${ }^{\mathrm{b}}$ Values are from mixed model for repeated measurement analysis.

${ }^{c}$ Values are from analysis of covariance.

$\mathrm{HbA}_{1 \mathrm{c}}$, hemoglobin $\mathrm{A}_{1 \mathrm{c}} ; \mathrm{LDL}$, low-density lipoprotein; LOCF, last observation carried forward; LS, least-squares; SD, standard deviation.

was $2.8 \%$ in the lurasidone $40 \mathrm{mg}$ /day group, $1.9 \%$ in the lurasidone $80 \mathrm{mg} /$ day group, and $4.5 \%$ in the placebo group. The mean change in QT interval corrected for heart rate-Fridericia's formula (QTcF) interval from baseline-was 2.4 milliseconds for lurasidone $40 \mathrm{mg} /$ day, 2.3 milliseconds for lurasidone $80 \mathrm{mg} /$ day, and -0.5 milliseconds for placebo. No patients in any treatment group had a QTcF $>460$ milliseconds or a postbaseline change in $\mathrm{QTcF} \geq 60$ milliseconds.

LS mean change at endpoint (ANCOVA) in the composite score from the Cogstate brief battery was not significantly different for the lurasidone $40 \mathrm{mg} /$ day group $(-0.09)$ or the lurasidone $80 \mathrm{mg} /$ day group (0.11) compared with the placebo group $(-0.10)$. No deleterious effects on cognition were observed.

\section{Discussion}

In this multicenter, placebo-controlled, short-term study, adolescent patients treated with lurasidone at fixed daily doses of 40 and $80 \mathrm{mg}$ demonstrated statistically significant and clinically meaningful improvement in symptoms of schizophrenia. For both doses, treatment with lurasidone was associated with significantly greater improvement, compared with placebo, in PANSS total score starting at week 1 and at all subsequent visits. Improvement was similar in younger (13-15 years) and older (16-17 years) patient cohorts. Consistent with these findings, lurasidone-treated patients in both dose groups showed significantly greater improvement relative to placebo on the CGI-S (key secondary outcome) and all PANSS subscales. In addition, treatment with both doses of lurasidone was associated with significant improvement in measures of functioning and quality of life. Given the reduction in quality of life, and the degree of social and developmental impairments observed in adolescents with schizophrenia there is a clear need for a multimodal approach that combines effective pharmacotherapy with psychological treatments, family-based therapy, and educational or vocational interventions.

Lurasidone has been extensively studied for the short- and longterm treatment of schizophrenia in adults (Loebel and Citrome 2015). Efficacy in this study of adolescents was generally compa- rable with that observed in short-term placebo-controlled studies of adults with schizophrenia (Nakamura et al. 2009; Meltzer et al. 2011; Loebel et al. 2013a; Nasrallah et al. 2013; Ogasa et al. 2013).

Treatment effect sizes for lurasidone, based on PANSS and CGI-S improvement, were comparable with effect sizes previously reported for other antipsychotic agents in short-term trials of adolescents with schizophrenia (Findling et al. 2008, 2012; Haas et al. 2009; Kryzhanovskaya et al. 2009; Singh et al. 2011; Findling et al. 2013, 2015b). Responder rates on lurasidone were significant for both doses (NNT $=5$ for each dose) and were also comparable with rates reported in previous short-term adolescent trials for other antipsychotic agents.

Safety and tolerability findings for lurasidone in this adolescent population differed from some other antipsychotic agents, with minimal effects on weight and metabolic parameters. In contrast, higher rates of weight gain, hyperlipidemia, and hyperglycemia have been reported in short-term trials of several other atypical antipsychotics in adolescent populations (Sikich et al. 2008; Correll et al. 2009; Correll 2011). The current results suggest that lurasidone may be associated with low cardiometabolic risk in adolescent patients, a population susceptible to antipsychotic-induced weight gain and metabolic dysfunction. In addition, minimal changes in prolactin levels and movement disorder assessments were observed in lurasidone-treated patients in this study.

Adverse events most commonly occurring on lurasidone in this study (e.g., nausea, akathisia, and somnolence) were consistent with the known safety profile of lurasidone in adults. Among adolescents studied, adverse events were typically rated as mild or moderate, with $<3 \%$ of lurasidone-treated patients experiencing events rated as severe, comparable with the incidence reported with placebo. The incidence of akathisia and extrapyramidal symptoms (EPS) during study treatment was relatively low, with no increase observed on the $80 \mathrm{mg} /$ day dose of lurasidone compared to the $40 \mathrm{mg} /$ day dose in either the incidence of akathisia/EPS or in the use of anticholinergic medications. In contrast, dose-related increases in akathisia/EPS have been reported in previous adolescent studies that have included two fixed doses (Findling et al. 2008, 2012; Haas et al. 2009). Overall, 
treatment with the $80 \mathrm{mg} /$ day dose of lurasidone did not appear to be associated with a consistently higher incidence or severity of adverse events when compared with the $40 \mathrm{mg} /$ day dose.

The comparable efficacy demonstrated for both doses of lurasidone in this study suggests that treatment of schizophrenia in adolescents should be initiated at $40 \mathrm{mg} / \mathrm{day}$ and should be increased to $80 \mathrm{mg} /$ day as needed based on efficacy and safety assessments.

Study limitations include the stringent inclusion and exclusion criteria, which may limit the generalizability of these results, and the relatively brief study duration. While this study supports the short-term safety and efficacy of lurasidone in adolescent patients with schizophrenia, further studies are needed to examine the longterm effectiveness of lurasidone in this patient population.

\section{Conclusions}

In this 6-week placebo-controlled study of efficacy and safety, lurasidone at fixed doses of 40 and $80 \mathrm{mg} /$ day provided statistically significant and clinically meaningful symptom improvement in adolescent patients with schizophrenia. Significant improvements in functional ability and quality of life were also observed. Lurasidone was generally well tolerated and had few effects on weight, metabolic parameters, and prolactin, similar to safety data in adult patients with schizophrenia.

\section{Clinical Significance}

We report here the findings from the first randomized placebocontrolled study of the efficacy and safety of lurasidone in the treatment of adolescents with schizophrenia. This study demonstrated that 6 weeks of treatment with lurasidone at fixed doses of 40 or $80 \mathrm{mg} /$ day provided significantly greater improvement compared with placebo on the PANSS total score (primary efficacy measure), the CGI-S (key secondary efficacy measure), and other secondary efficacy outcomes, including functional impairment and quality of life. Adverse events associated with lurasidone (e.g., nausea, akathisia, and somnolence) and minimal effects of treatment on weight and metabolic parameters were consistent with the safety profile in adults with schizophrenia. The results of this study support lurasidone as an efficacious and well-tolerated treatment option for adolescent patients with schizophrenia.

\section{Acknowledgments}

Editorial and medical writing support was provided by Nancy Holland, PhD, of Synchrony Medical Communications, LLC, under the direction of the authors and was funded by Sunovion Pharmaceuticals, Inc., Marlborough, MA. Clinical research was sponsored by Sunovion Pharmaceuticals, Inc. The sponsor was involved in the study design, collection, and analysis of data. The interpretation of results and the decision to submit this article for publication in the Journal of Child and Adolescent Psychopharmacology were made by the authors independently. ClinicalTrials.gov identifier: NCT01911429.

\section{Disclosures}

Drs. R.G., A.L., J.C., and L.D. are employees of Sunovion Pharmaceuticals, Inc. In the last 36 months, Dr. R.L.F. received or has received research support, acted as a consultant, and/or served on a speaker's bureau for Actavis, Akili, Alcobra, American Academy of Child and Adolescent Psychiatry, American Psychiatric Press, Bracket, CogCubed, Cognition Group, Coronado Biosciences, Elsevier, Epharma Solutions, Forest, Genentech, GlaxoSmithKline, Guilford Press, Ironshore, Johns Hopkins University Press, Kem-
Pharm, Lundbeck, Medgenics, Merck, NIH, Neurim, Novartis, Otsuka, PCORI, Pfizer, Physicians Postgraduate Press, Purdue, Rhodes Pharmaceuticals, Roche, Sage, Shire, Sunovion, Supernus Pharmaceuticals, Syneurx, Takeda, Teva, Tris, Validus, and WebMD.

\section{References}

Andreasen NC, Carpenter WT Jr., Kane JM, et al.: Remission in schizophrenia: Proposed criteria and rationale for consensus. Am J Psychiatry 162:441-449, 2005.

Barnes TR: A rating scale for drug-induced akathisia. Br J Psychiatry 154:672-676, 1989.

Beratis S, Gabriel J, Hoidas S: Age at onset in subtypes of schizophrenic disorders. Schizophr Bull 20:287-296, 1994.

Citrome L, Cucchiaro J, Sarma K, Phillips D, Silva R, Tsuchiya S, Loebel A: Long-term safety and tolerability of lurasidone in schizophrenia: A 12-month, double-blind, active-controlled study. Int Clin Psychopharmacol 27:165-176, 2012.

Clemmensen L, Vernal DL, Steinhausen HC: A systematic review of the long-term outcome of early onset schizophrenia. BMC Psychiatry 12:150, 2012.

Correll CU: Safety and tolerability of antipsychotic treatment in young patients with schizophrenia. J Clin Psychiatry 72:e26, 2011.

Correll CU, Manu P, Olshanskiy V, Napolitano B, Kane JM, Malhotra AK: Cardiometabolic risk of second-generation antipsychotic medications during first-time use in children and adolescents. JAMA 302:1765-1773, 2009.

De Hert M, Dobbelaere M, Sheridan EM, Cohen D, Correll CU: Metabolic and endocrine adverse effects of second-generation antipsychotics in children and adolescents: A systematic review of randomized, placebo controlled trials and guidelines for clinical practice. Eur Psychiatry 26:144-158, 2011.

Dmitrienko A, Millen BA, Brechenmacher T, Paux G: Development of gatekeeping strategies in confirmatory clinical trials. Biom J 53:875-893, 2011.

Endicott J, Nee J, Yang R, Wohlberg C: Pediatric Quality of Life Enjoyment and Satisfaction Questionnaire (PQ-LES-Q): Reliability and validity. J Am Acad Child Adolesc Psychiatry 45:401-407, 2006.

Findling RL, Cavus I, Pappadopulos E, Vanderburg DG, Schwartz JH, Gundapaneni BK, DelBello MP: Ziprasidone in adolescents with schizophrenia: Results from a placebo-controlled efficacy and longterm open-extension study. J Child Adolesc Psychopharmacol 23: 531-544, 2013.

Findling RL, Goldman R, Chiu YY, Silva R, Jin F, Pikalov A, Loebel A: Pharmacokinetics and tolerability of lurasidone in children and adolescents with psychiatric disorders. Clin Ther 37:2788-2797, 2015a.

Findling RL, Landbloom RP, Mackle M, Pallozzi W, Braat S, Hundt C, Wamboldt MZ, Mathews M: Safety and efficacy from an 8 week double-blind trial and a 26 week open-label extension of asenapine in adolescents with schizophrenia. J Child Adolesc Psychopharmacol 25:384-396, 2015b.

Findling RL, McKenna K, Earley WR, Stankowski J, Pathak S: Efficacy and safety of quetiapine in adolescents with schizophrenia investigated in a 6-week, double-blind, placebo-controlled trial. J Child Adolesc Psychopharmacol 22:327-342, 2012.

Findling RL, Robb A, Nyilas M, Forbes RA, Jin N, Ivanova S, Marcus R, McQuade RD, Iwamoto T, Carson WH: A multiple-center, randomized, double-blind, placebo-controlled study of oral aripiprazole for treatment of adolescents with schizophrenia. Am J Psychiatry 165:1432-1441, 2008.

Fleischhaker C, Schulz E, Tepper K, Martin M, Hennighausen K, Remschmidt H: Long-term course of adolescent schizophrenia. Schizophr Bull 31:769-780, 2005.

Frazier JA, Giuliano AJ, Johnson JL, Yakutis L, Youngstrom EA, Breiger D, Sikich L, Findling RL, McClellan J, Hamer RM, Vitiello 
B, Lieberman JA, Hooper SR: Neurocognitive outcomes in the treatment of early-onset schizophrenia spectrum disorders study. J Am Acad Child Adolesc Psychiatry 51:496-505, 2012.

Frazier JA, McClellan J, Findling RL, Vitiello B, Anderson R, Zablotsky B, Williams E, McNamara NK, Jackson JA, Ritz L, Hlastala SA, Pierson L, Varley JA, Puglia M, Maloney AE, Ambler D, Hunt-Harrison T, Hamer RM, Noyes N, Lieberman JA, Sikich L: Treatment of early-onset schizophrenia spectrum disorders (TEOSS): Demographic and clinical characteristics. J Am Acad Child Adolesc Psychiatry 46:979-988, 2007.

Guy W: ECDEU Assessment Manual for Psychopharmacology Revised. Rockville, MD, US Department of Health, Education, and Welfare, National Institute of Mental Health, 1976.

Haas M, Unis AS, Armenteros J, Copenhaver MD, Quiroz JA, Kushner SF: A 6-week, randomized, double-blind, placebo-controlled study of the efficacy and safety of risperidone in adolescents with schizophrenia. J Child Adolesc Psychopharmacol 19:611-621, 2009.

Hafner H, Maurer K, Loffler W, Riecher-Rossler A: The influence of age and sex on the onset and early course of schizophrenia. Br J Psychiatry 162:80-86, 1993.

Hafner H, Nowotny B: Epidemiology of early-onset schizophrenia. Eur Arch Psychiatry Clin Neurosci 245:80-92, 1995.

Hollis C: Adult outcomes of child- and adolescent-onset schizophrenia: Diagnostic stability and predictive validity. Am J Psychiatry 157:1652-1659, 2000.

Ishibashi T, Horisawa T, Tokuda K, Ishiyama T, Ogasa M, Tagashira R, Matsumoto K, Nishikawa H, Ueda Y, Toma S, Oki H, Tanno N, Saji I, Ito A, Ohno Y, Nakamura M: Pharmacological profile of lurasidone, a novel antipsychotic agent with potent 5-hydroxytryptamine $7\left(5-\mathrm{HT}_{7}\right)$ and 5- $\mathrm{HT}_{1 \mathrm{~A}}$ receptor activity. J Pharmacol Exp Ther 334:171-181, 2010.

Kay SR, Fiszbein A, Opler LA: The positive and negative syndrome scale (PANSS) for schizophrenia. Schizophr Bull 13:261-276, 1987.

Kryzhanovskaya L, Schulz SC, McDougle C, Frazier J, Dittmann R, Robertson-Plouch C, Bauer T, Xu W, Wang W, Carlson J, Tohen M: Olanzapine versus placebo in adolescents with schizophrenia: A 6-week, randomized, double-blind, placebo-controlled trial. J Am Acad Child Adolesc Psychiatry 48:60-70, 2009.

Lay B, Blanz B, Hartmann M, Schmidt MH: The psychosocial outcome of adolescent-onset schizophrenia: A 12-year followup. Schizophr Bull 26:801-816, 2000.

Lingjaerde O, Ahlfors UG, Bech P, Dencker SJ, Elgen K: The UKU side effect rating scale. A new comprehensive rating scale for psychotropic drugs and a cross-sectional study of side effects in neuroleptic-treated patients. Acta Psychiatr Scand Suppl 334:1-100, 1987.

Loebel A, Citrome L: Lurasidone: A novel antipsychotic agent for the treatment of schizophrenia and bipolar depression. BJPsych Bull 39:237-241, 2015.

Loebel A, Cucchiaro J, Sarma K, Xu L, Hsu C, Kalali AH, Pikalov A, Potkin SG: Efficacy and safety of lurasidone $80 \mathrm{mg} /$ day and $160 \mathrm{mg} /$ day in the treatment of schizophrenia: A randomized, double-blind, placeboand active-controlled trial. Schizophr Res 145:101-109, 2013a.

Loebel A, Cucchiaro J, Xu J, Sarma K, Pikalov A, Kane JM: Effectiveness of lurasidone vs. quetiapine XR for relapse prevention in schizophrenia: A 12-month, double-blind, noninferiority study. Schizophr Res 147:95-102, 2013 b.

Maayan L, Correll CU: Weight gain and metabolic risks associated with antipsychotic medications in children and adolescents. J Child Adolesc Psychopharmacol 21:517-535, 2011.

Maruff P, Thomas E, Cysique L, Brew B, Collie A, Snyder P, Pietrzak RH: Validity of the CogState brief battery: Relationship to standardized tests and sensitivity to cognitive impairment in mild traumatic brain injury, schizophrenia, and AIDS dementia complex. Arch Clin Neuropsychol 24:165-178, 2009.
Masi G, Liboni F: Management of schizophrenia in children and adolescents: Focus on pharmacotherapy. Drugs 71:179-208, 2011. McClellan J, Stock S: Practice parameter for the assessment and treatment of children and adolescents with schizophrenia. J Am Acad Child Adolesc Psychiatry 52:976-990, 2013.

Meltzer HY, Cucchiaro J, Silva R, Ogasa M, Phillips D, Xu J, Kalali AH, Schweizer E, Pikalov A, Loebel A: Lurasidone in the treatment of schizophrenia: A randomized, double-blind, placebo- and olanzapine-controlled study. Am J Psychiatry 168:957-967, 2011.

Munetz MR, Benjamin S: How to examine patients using the Abnormal Involuntary Movement Scale. Hosp Community Psychiatry 39:1172-1177, 1988.

Nakamura M, Ogasa M, Guarino J, Phillips D, Severs J, Cucchiaro J, Loebel A: Lurasidone in the treatment of acute schizophrenia: A double-blind, placebo-controlled trial. J Clin Psychiatry 70:829836, 2009.

Nasrallah HA, Silva R, Phillips D, Cucchiaro J, Hsu J, Xu J, Loebel A: Lurasidone for the treatment of acutely psychotic patients with schizophrenia: A 6-week, randomized, placebo-controlled study. J Psychiatr Res 47:670-677, 2013.

Ogasa M, Kimura T, Nakamura M, Guarino J: Lurasidone in the treatment of schizophrenia: A 6-week, placebo-controlled study. Psychopharmacology (Berl) 225:519-530, 2013.

Posner K, Brown GK, Stanley B, Brent DA, Yershova KV, Oquendo MA, Currier GW, Melvin GA, Greenhill L, Shen S, Mann JJ: The Columbia-Suicide Severity Rating Scale: Initial validity and internal consistency findings from three multisite studies with adolescents and adults. Am J Psychiatry 168:1266-1277, 2011.

Shaffer D, Gould MS, Brasic J, Ambrosini P, Fisher P, Bird H, Aluwahlia S: A children's global assessment scale (CGAS). Arch Gen Psychiatry 40:1228-1231, 1983.

Sikich L, Frazier JA, McClellan J, Findling RL, Vitiello B, Ritz L, Ambler D, Puglia M, Maloney AE, Michael E, De JS, Slifka K, Noyes N, Hlastala S, Pierson L, McNamara NK, Delporto-Bedoya D, Anderson R, Hamer RM, Lieberman JA: Double-blind comparison of first- and second-generation antipsychotics in early-onset schizophrenia and schizo-affective disorder: Findings from the treatment of early-onset schizophrenia spectrum disorders (TEOSS) study. Am J Psychiatry 165:1420-1431, 2008.

Simpson GM, Angus JW: A rating scale for extrapyramidal side effects. Acta Psychiatr Scand Suppl 212:11-19, 1970.

Singh J, Robb A, Vijapurkar U, Nuamah I, Hough D: A randomized, double-blind study of paliperidone extended-release in treatment of acute schizophrenia in adolescents. Biol Psychiatry 70:1179-1187, 2011.

Tandon R, Cucchiaro J, Phillips D, Hernandez D, Mao Y, Pikalov A, Loebel A: A double-blind, placebo-controlled, randomized withdrawal study of lurasidone for the maintenance of efficacy in patients with schizophrenia. J Psychopharmacol 30:69-77, 2016.

Vitiello B, Correll C, van Zwieten-Boot B, Zuddas A, Parellada M, Arango C: Antipsychotics in children and adolescents: Increasing use, evidence for efficacy and safety concerns. Eur Neuropsychopharmacol 19:629-635, 2009.

Young CM, Findling RL: Pharmacologic treatment of adolescent and child schizophrenia. Expert Rev Neurother 4:53-60, 2004.

Address correspondence to: Robert Goldman, PhD Sunovion Pharmaceuticals, Inc. 84 Waterford Drive Marlborough, MA 01752-7010

E-mail: robert.goldman@sunovion.com 